\title{
Predictors of Mortality in Acute Kidney Injury Patients Admitted to Medicine Intensive Care Unit in a Rural Tertiary Care Hospital
}

\author{
Amrish Saxena, Shrikant V. Meshram \\ Department of Medicine, Mahatma Gandhi Institute of Medical Sciences, Wardha, Maharashtra, India
}

\section{Abstract}

Background: Acute kidney injury (AKI) is a challenging problem faced by intensive care clinicians worldwide, and it is associated with high morbidity and mortality, especially in critically ill patients. Materials and Methods: A hospital-based prospective, observational study was conducted in patients of AKI admitted to the Intensive Care Unit (ICU) of the Department of Medicine in a rural tertiary care hospital located in central India. Data of all consecutive AKI inpatients related to demographic variables, clinical profile, and laboratory investigations were collected from patient's medical records. Results: Of the total 229 AKI patients enrolled in this study, 65 (28.4\%) patients died during their hospital stay. The presence of metabolic acidosis, hypotension, Glasgow coma scale (GCS) and Acute Physiologic Assesment and Chronic Health Evaluation (APACHE 2) score, advanced AKI stage, higher serum creatinine and blood urea levels on diagnosis of AKI and the peak rise in their level within $48 \mathrm{~h}$ of diagnosis of AKI, the use of mechanical ventilator, leukocytosis, and hyperkalemia were significantly associated with in-hospital mortality in AKI patients $(P<0.05)$. Conclusion: The overall in-hospital mortality in patients of AKI admitted to medicine-ICU was $28.4 \%$. Sepsis was the most common cause of AKI (24.5\%). The presence of metabolic acidosis, hypotension, GCS and APACHE 2 score, advanced AKI stage, higher serum creatinine, and blood urea levels on diagnosis of AKI and the peak rise in their level within $48 \mathrm{~h}$ of diagnosis of AKI, use of mechanical ventilator, leukocytosis, and hyperkalemia were associated with in-hospital mortality in AKI patients.

Keywords: Acute kidney injury, etiology, incidence, mortality, predictors

\section{INTRODUCTION}

Acute kidney injury (AKI) is characterized by rapid decline in kidney function over a period of hours to days resulting in retention of metabolic waste products. ${ }^{[1,2]} \mathrm{AKI}$ is a challenging problem in low-resource settings due to the high burden of infectious diseases, diarrheal illnesses, snake bites, the over-the-counter availability of potentially nephrotoxic drugs, and medicinal herbs.

The previous studies showed that $3 \%-7 \%$ of hospitalized patients and $25 \%-30 \%$ of patients in the Intensive Care Unit (ICU) develop AKI, with 5\%-6\% of the ICU population requiring renal replacement therapy after developing AKI. ${ }^{[3-5]}$ AKI in ICU is associated with high mortality, longer hospital stay, and substantial health resource utilization. ${ }^{[6,7]}$ In addition, the previous studies have revealed that patients who recover from AKI are at increased risk of progressive chronic kidney disease (CKD) and development of end-stage renal disease (ESRD). ${ }^{[8-10]}$

\begin{tabular}{|l|l|}
\hline \multicolumn{3}{c|}{ Access this article online } \\
\hline Quick Response Code: & Website: \\
& www.ijccm.org \\
\hline
\end{tabular}

The identification of factors associated with mortality among patients hospitalized for AKI would help in establishing interventions or preventive measures that could improve survival in AKI patients. In view of the limited data, on hospitalized AKI patients, from resource-limited countries and its likely importance, this study was planned to assess the clinical profile and factors affecting the mortality in AKI patients in our setting, i.e., a rural tertiary care hospital located in central India.

\section{Materials and Methods}

A prospective, observational study was conducted in patients of AKI admitted to the ICU of the Department of medicine in a

Address for correspondence: Dr. Amrish Saxena MLK-5, MGIMS Campus, Sevagram, Wardha, Maharashtra, India. E-mail: dramrishsaxena@rediffmail.com

This is an open access journal, and articles are distributed under the terms of the Creative Commons Attribution-NonCommercial-ShareAlike 4.0 License, which allows others to remix, tweak, and build upon the work non-commercially, as long as appropriate credit is given and the new creations are licensed under the identical terms.

For reprints contact: reprints@medknow.com

How to cite this article: Saxena A, Meshram SV. Predictors of mortality in acute kidney injury patients admitted to medicine Intensive Care Unit in a rural tertiary care hospital. Indian J Crit Care Med 2018;22:231-7. 
rural tertiary care hospital located in a town in central India over a period of 18 months from November 1, 2014, to April 30, 2016.

\section{Inclusion criteria}

All consecutive patients of AKI, 18 years of age or older admitted to medical ICU with AKI, or developed AKI after hospitalization and fulfill the Kidney Disease Improving Global Outcomes definition. ${ }^{[11]}$ For this study, AKI is defined as an acute increase in serum creatinine by $\geq 0.3 \mathrm{mg} / \mathrm{dL}$ within $48 \mathrm{~h}$, an increase of 1.5-fold or more in baseline serum creatinine level within the previous 7 days, or reduction in urine output $<0.5 \mathrm{~mL} / \mathrm{kg} / \mathrm{h}$ for $6 \mathrm{~h}$.

\section{Exclusion criteria}

Patients with CKD or ESRD, patients with age $<18$ years, withdrawal of treatment during the ICU stay, discharge against medical advice, AKI patients with incomplete data and AKI patients who did not wish to participate were not included in this study.

Demographic variables (age, gender, socioeconomic status, and education), clinical profile, diagnosis, comorbidities (hypertension [HTN] and diabetes mellitus [DM], ischemic heart disease [IHD]), alcohol intake, smoking history, the presence of hypotension, use of mechanical ventilator, the presence of sepsis, need for hemodialysis during hospitalization, urine output (oliguric or nonoliguric), outcomes (death/survived), and laboratory investigations-serum creatinine 1: serum creatinine on diagnosis of AKI, serum creatinine 2 : difference between peak value of serum creatinine (within 48 hours of diagnosis of AKI) and serum creatinine on diagnosis of AKI, blood urea 1: blood urea on diagnosis of AKI, blood urea 2: difference between peak value of blood urea (within 48 hours of diagnosis of AKI) and blood urea on diagnosis of AKI, sodium, potassium, hemoglobin, total leukocyte count, and the presence of metabolic acidosis were collected from medical records of the AKI patients. Oliguria was considered to be present when the urinary volume was $<400 \mathrm{~mL} /$ day. ICU scores-Acute Physiologic Assessment and Chronic Health Evaluation (APACHE 2) score and Glasgow coma scale (GCS) scores of the AKI patients were also recorded. Sepsis was defined as two or more of the following four conditions: (1) Fever (oral temperature $>38^{\circ} \mathrm{C}$ ) or hypothermia $\left(<36^{\circ} \mathrm{C}\right)$; $(2)$ tachypnea ( $>24$ breaths/min); (3) tachycardia (heart rate $>90$ beats/min); and (4) leukocytosis $(>12,000 / \mu \mathrm{L})$, leukopenia $(<4000 / \mu \mathrm{L})$, or $>10 \%$ bands, has a proven or suspected microbial etiology and sequential organ failure assessment score of $\geq 2$.

AKI was further classified into three stages according to the severity of kidney injury.

1. AKI Stage 1: increase in serum creatinine by $\geq 0.3 \mathrm{mg} / \mathrm{dL}$ or 1.5-1.9 times baseline

2. AKI Stage 2: increase in serum creatinine by $2.0-2.9$ times baseline

3. AKI Stage 3: increase in serum creatinine of $\geq 3.0$ times baseline or serum creatinine more than $4 \mathrm{mg} / \mathrm{dL}$ or initiation of renal replacement therapy.
In patients with shock or hypotension, point-of-care ultrasonography including rapid ultrasound in shock was used to look for inferior vena cava collapsibility, focused cardiac ultrasound with bedside clinical, and hemodynamic signs were used to assess volume status of the patients. We used crystalloid solution (normal saline) for fluid resuscitation.

We used sustained low-efficiency dialysis in few hemodynamically unstable AKI patients. We did not use continuous renal replacement therapy in any patient, as this facility is not available in our hospital.

\section{Patient follow-up}

The AKI patients were prospectively, monitored up to hospital discharge on a regular basis. At discharge, they were classified as nonsurvivors or survivors. Renal recovery in this study means dialysis independence at the time of hospital discharge and return of serum creatinine to within $20 \%$ of preAKI creatinine/baseline creatinine.

\section{Statistical analysis used}

Patients were categorized as survivors or nonsurvivors, and variables (demographic, clinical, and biochemical variables) were compared using bivariate analysis. Statistical analysis was performed using descriptive and inferential statistics. The Chi-squared test was used for the comparison of proportions of categorical variables and $z$-test for the difference between two means. Data were analyzed using the SPSS software 17.0 version (SPSS South Asia Private Limited, Bangalore, Karnataka, India). A value of $P<0.05$ was considered as statistically significant.

\section{RESULTS}

We enrolled a total of 229 patients of AKI over an 18-month period. Three thousand five hundred eighty-four patients admitted to medicine ICU during this period. A total of 245 patients developed AKI during this period, out of which 16 patients were excluded as per the study exclusion criteria. The mean age was $49.76 \pm 17.01$ years ranging from 18 to 92 years. There were $36(15.7 \%)$ AKI patients below the age of 30 years, $122(53.3 \%)$ AKI patients between 30 and 60 years, and 71 (31\%) AKI patients were above the age of 60 years [Table 1]. Of the total 229 patients of AKI, $71(31 \%)$ were male, and $158(69 \%)$ were female [Table 1]. The association of age of patients ( $<30$ years, 30-60 years, and $>60$ years) and gender of the patients with the in-hospital mortality was not statistically significant $(P>0.05)$ [Table 1].

Of the 229 AKI patients, $86(37.6 \%)$ had HTN, $63(27.5 \%)$ had DM, and 43 (18.8\%) had IHD. The association of comorbidities (HTN, DM, and IHD) with in-hospital mortality was not statistically significant [Table 2].

There were $34(14.8 \%)$ current smokers and $41(17.9 \%)$ alcohol drinkers of the total 229 AKI patients. The association of in-hospital mortality with either current smoking or alcohol drinking was not statistically significant [Table 2]. 


\begin{tabular}{|c|c|c|c|c|}
\hline Demographic variables & Nonsurvivors ( $n=65), n$ (\%) & Survivors $(n=164), n(\%)$ & Total $(n=229), n(\%)$ & $P$ \\
\hline \multicolumn{5}{|l|}{ Age-groups (years) } \\
\hline$<30$ & $10(15.4)$ & $26(15.9)$ & $36(15.7)$ & 0.75 \\
\hline $30-60$ & $37(56.9)$ & $85(51.8)$ & $122(53.3)$ & \\
\hline$>60$ & $18(27.7)$ & $53(32.3)$ & $71(31)$ & \\
\hline \multicolumn{5}{|l|}{ Gender } \\
\hline Male & $21(32.3)$ & $50(30.5)$ & $71(31)$ & 0.78 \\
\hline Female & $44(67.7)$ & $114(69.5)$ & $158(69)$ & \\
\hline
\end{tabular}

Figures in parenthesis represent the column percentage

\begin{tabular}{|c|c|c|c|c|}
\hline Comorbidities/habitual history & Nonsurvivors ( $n=65), n(\%)$ & Survivors $(n=164), n(\%)$ & Total $(n=229), n(\%)$ & $P$ \\
\hline \multicolumn{5}{|l|}{ HTN } \\
\hline Present & $25(38.5)$ & $61(37.2)$ & $86(37.6)$ & 0.85 \\
\hline Absent & $40(61.5)$ & $103(62.8)$ & $143(62.4)$ & \\
\hline \multicolumn{5}{|l|}{$\mathrm{DM}$} \\
\hline Present & $18(27.7)$ & $45(27.4)$ & $63(27.5)$ & 0.96 \\
\hline Absent & $47(72.3)$ & $119(72.6)$ & $166(72.5)$ & \\
\hline \multicolumn{5}{|l|}{ IHD } \\
\hline Present & $9(13.8)$ & $34(20.7)$ & $43(18.8)$ & 0.22 \\
\hline Absent & $56(86.2)$ & $130(79.3)$ & $186(81.2)$ & \\
\hline \multicolumn{5}{|l|}{ Alcohol intake } \\
\hline Present & $9(13.8)$ & $32(19.5)$ & $41(17.9)$ & 0.31 \\
\hline Absent & $56(86.2)$ & $132(80.5)$ & $188(82.1)$ & \\
\hline \multicolumn{5}{|l|}{ Current smokers } \\
\hline Present & $11(16.9)$ & $23(14)$ & $34(14.8)$ & 0.57 \\
\hline Absent & $54(83.1)$ & $141(86)$ & $195(85.2)$ & \\
\hline
\end{tabular}

Figures in parenthesis represent the column percentage. HTN: Hypertension; DM: Diabetes mellitus; IHD: Ischemic heart disease

Of the 229 AKI patients, 80 (34.9\%) had Stage 1 AKI, $98(42.8 \%)$ had Stage 2 AKI, and $51(22.3 \%)$ had Stage 3 AKI [Table 3]. The association of staging of AKI patients (severity) with the in-hospital mortality was found to be statistically significant $(P<0.05)$ [Table 3 ].

One hundred and sixteen (50.7\%) of 229 patients had oliguria. Hypotension was present in 90 AKI patients (39.3\%). One hundred and seventy-six (76.9\%) had metabolic acidosis. The invasive mechanical ventilator was used in $70 \mathrm{AKI}$ patients $(30.6 \%)$. Hemodialysis was done in $71 \mathrm{AKI}$ patients (31\%) [Table 4].

The association of urine output and the use of hemodialysis in AKI patients with in-hospital mortality was not statistically significant $(P>0.05)$ [Table 4]. The presence of hypotension and the use of an invasive mechanical ventilator in AKI patients were found to be significantly associated with in-hospital mortality $(P<0.05)$ [Table 4]. The mean number of hemodialysis sessions done in our AKI patients was $4.4 \pm 1.3$ (ranges from 2 to 8 ).

Fifty-three (23.1\%) of the 229 AKI patients had GCS $<10$ and $176(76.9 \%)$ had GCS $>10$ [Table 5]. Forty-four patients (19.2\%) had APACHE 2 score $\leq 15,128$ patients $(55.8 \%)$ had APACHE 2 score between 16 and 30, and 57 patients

\begin{tabular}{|c|c|c|c|c|}
\hline $\begin{array}{l}\text { Stages } \\
\text { of AKI }\end{array}$ & $\begin{array}{l}\text { Nonsurvivors } \\
(n=65), n(\%)\end{array}$ & $\begin{array}{c}\text { Survivors } \\
(n=164), n(\%)\end{array}$ & $\begin{array}{c}\text { Total }(n=229), \\
n(\%)\end{array}$ & $P$ \\
\hline Stage 1 & $7(10.8)$ & $73(44.5)$ & $80(34.9)$ & 0.001 \\
\hline Stage 2 & $35(53.8)$ & $63(38.4)$ & $98(42.8)$ & \\
\hline Stage 3 & $23(35.4)$ & $28(17.1)$ & $51(22.3)$ & \\
\hline
\end{tabular}

Figures in parenthesis represent the column percentage. AKI: Acute kidney injury

(25\%) had APACHE 2 score $\geq 31$ [Table 5]. Both GCS and APACHE 2 score were found to be significantly associated with in-hospital mortality $(P<0.05)$.

The mean serum creatinine value was $3.10 \pm 1.69$ and $3.82 \pm 2.01 \mathrm{mg} / \mathrm{dL}$ among survivors and nonsurvivors, respectively. The mean blood urea was $101.83 \pm 70.31$ and $123.53 \pm 73.86 \mathrm{mg} / \mathrm{dL}$ among survivors and nonsurvivors, respectively [Table 6].

Serum creatinine on diagnosis of AKI, peak rise in serum creatinine within $48 \mathrm{~h}$ of diagnosis of AKI, blood urea on diagnosis of AKI, and peak rise in blood urea within $48 \mathrm{~h}$ of diagnosis of $\mathrm{AKI}$, and bicarbonate $\left(\mathrm{HCO}^{3-}\right)$ levels were found to 


\begin{tabular}{|c|c|c|c|c|}
\hline Clinical variables/interventions used & Nonsurvivors $(n=65), n(\%)$ & Survivors $(n=164), n(\%)$ & Total $(n=229), n(\%)$ & $P$ \\
\hline \multicolumn{5}{|l|}{$\mathrm{UO}$} \\
\hline Oliguric & $40(61.5)$ & $76(46.3)$ & $116(50.7)$ & 0.11 \\
\hline Nonoliguric & $25(38.5)$ & $88(53.7)$ & $113(49.3)$ & \\
\hline \multicolumn{5}{|l|}{ Hypotension } \\
\hline Present & $49(75.4)$ & $41(25)$ & $90(39.3)$ & 0.0001 \\
\hline Absent & $16(24.6)$ & $123(75)$ & $139(60.7)$ & \\
\hline \multicolumn{5}{|l|}{ Invasive mechanical ventilator } \\
\hline Used & $49(75.4)$ & $21(12.8)$ & $70(30.6)$ & 0.0001 \\
\hline Not used & $16(24.6)$ & $143(87.2)$ & $159(69.4)$ & \\
\hline \multicolumn{5}{|l|}{ Hemodialysis } \\
\hline Used & $22(33.8)$ & $49(29.9)$ & $71(31)$ & 0.55 \\
\hline Not used & $43(66.2)$ & $115(70.1)$ & $158(69)$ & \\
\hline
\end{tabular}

Figures in parenthesis represent the column percentage. UO: Urine output

\begin{tabular}{|c|c|c|c|c|}
\hline ICU scores & Nonsurvivors $(n=65), n(\%)$ & Survivors $(n=164), n(\%)$ & Total $(n=229), n(\%)$ & $P$ \\
\hline \multicolumn{5}{|l|}{ GCS score } \\
\hline$<10$ & $30(46.2)$ & $23(14)$ & $53(23.1)$ & 0.001 \\
\hline $11-15$ & $35(53.8)$ & $141(86)$ & $176(76.9)$ & \\
\hline \multicolumn{5}{|c|}{ APACHE 2 score } \\
\hline $0-15$ & $1(1.5)$ & $43(26.2)$ & $44(19.2)$ & 0.0001 \\
\hline $16-30$ & $22(33.9)$ & $106(64.6)$ & $128(55.8)$ & \\
\hline$>31$ & $42(64.6)$ & $15(9.2)$ & $57(25)$ & \\
\hline
\end{tabular}

Figures in parenthesis represent the column percentage. ICU: Intensive Care Unit; GCS: Glasgow Coma Scale; APACHE: Acute Physiologic Assessment and Chronic Health Evaluation

Table 6: Comparison of laboratory parameters among survivors and nonsurvivors

\begin{tabular}{|c|c|c|c|c|c|c|}
\hline Laboratory parameters & Status & $n$ & Mean \pm SD & SEM & $Z$ & $P$ \\
\hline \multirow[t]{2}{*}{ Serum creatinine 1} & Nonsurvivors & 65 & $3.82 \pm 2.01$ & 0.24 & 2.73 & 0.007 \\
\hline & Survivors & 164 & $3.10 \pm 1.69$ & 0.13 & & \\
\hline \multirow[t]{2}{*}{ Serum creatinine 2} & Nonsurvivors & 65 & $0.90 \pm 1.42$ & 0.17 & 3.34 & 0.001 \\
\hline & Survivors & 164 & $0.40 \pm 1.20$ & 0.09 & & \\
\hline \multirow[t]{2}{*}{ Blood urea 1} & Nonsurvivors & 65 & $123.53 \pm 73.86$ & 8.72 & 2.03 & 0.043 \\
\hline & Survivors & 164 & $101.83 \pm 60.31$ & 5.76 & & \\
\hline \multirow[t]{2}{*}{ Blood urea 2} & Nonsurvivors & 65 & $36.27 \pm 68.52$ & 8.49 & 3.21 & 0.002 \\
\hline & Survivors & 164 & $12.15 \pm 53.95$ & 5.77 & & \\
\hline \multirow[t]{2}{*}{ Serum bicarbonate } & Nonsurvivors & 65 & $16.34 \pm 4.83$ & 0.60 & 2.83 & 0.005 \\
\hline & Survivors & 164 & $18.19 \pm 4.31$ & 0.33 & & \\
\hline \multirow[t]{2}{*}{ Hemoglobin } & Nonsurvivors & 65 & $10.99 \pm 2.79$ & 0.34 & 0.10 & 0.91 \\
\hline & Survivors & 164 & $10.94 \pm 3.32$ & 0.25 & & \\
\hline \multirow[t]{2}{*}{ Serum sodium } & Nonsurvivors & 65 & $132.03 \pm 9.99$ & 1.036 & 0.24 & 0.67 \\
\hline & Survivors & 164 & $131.6 \pm 9.24$ & 0.948 & & \\
\hline
\end{tabular}

Serum creatinine 1: Serum creatinine on diagnosis of AKI; Serum creatinine 2: difference between peak value of serum creatinine (within 48 hours of diagnosis of AKI) and serum creatinine on diagnosis of AKI; blood urea 1: blood urea on diagnosis of AKI; blood urea 2: difference between peak value of blood urea (within 48 hours of diagnosis of AKI) and blood urea on diagnosis of AKI $n$ : Number of AKI patients; SD: Standard deviation; SEM: Standard error of mean; AKI: Acute kidney injury

be significantly associated with in-hospital mortality $(P<0.05)$ [Table 6]. The mean $\mathrm{HCO}^{3-}$ levels were $18.2 \pm 4.3$ and $16.3 \pm 4.8$ $\mathrm{mEq} / \mathrm{L}$ among survivors and nonsurvivors, respectively [Table 6]. The mean Hb level was $10.9 \mathrm{~g} / \mathrm{dl}( \pm 3.17)$ in both the survivors and nonsurvivors group. Hemoglobin of AKI patients was not related to in-hospital mortality $(P>0.05)$ [Table 6].
Hyperkalemia and leukocytosis were present in 66 AKI patients (28.8\%) and 156 AKI patients (68.1\%), respectively. Both hyperkalemia and leukocytosis were significantly associated with in-hospital mortality $(P<0.05)$ [Table 7]. The mean serum potassium level of AKI patients having hyperkalemia was $6.08( \pm 0.65)$ which is mild $(5.5-6.5 \mathrm{mEq} / \mathrm{L})$. 
Saxena and Meshram: Predictors of mortality in AKI patients

\begin{tabular}{|c|c|c|c|c|}
\hline Laboratory parameters & Nonsurvivors $(n=65), n(\%)$ & Survivors $(n=164), n(\%)$ & Total $(n=229), n(\%)$ & $P$ \\
\hline \multicolumn{5}{|l|}{ Hyperkalemia } \\
\hline Present & $25(38.5)$ & $41(25)$ & $66(28.8)$ & 0.043 \\
\hline Absent & $40(61.5)$ & $123(75)$ & $163(71.2)$ & \\
\hline \multicolumn{5}{|l|}{ Leukocytosis } \\
\hline Present & $54(83.1)$ & $102(62.2)$ & $156(68.1)$ & 0.002 \\
\hline Absent & $11(16.9)$ & $62(37.8)$ & $73(31.9)$ & \\
\hline
\end{tabular}

Figures in parenthesis represent the column percentage

The most common cause of AKI in our medicine ICU patients was sepsis $(24.5 \%)$ followed by snake bite $(16.2 \%)$, acute gastroenteritis $(12.6 \%)$, cirrhosis $(7 \%)$, congestive cardiac failure $(5.2 \%)$, malaria (4.7\%), CV stroke (4.4\%), obstructive uropathy $(4.4 \%)$, acute respiratory distress syndrome $(3.5 \%)$, sickle cell disease $(3.1 \%)$, dengue $(3.1 \%)$, organophosphorus poisoning $(2.6 \%)$, acute pancreatitis $(2.2 \%)$, contrast-induced AKI (1.7\%), scrub typhus (1.3\%), HELLP syndrome $(1.3 \%)$, hemolytic uremic syndrome $(0.9 \%)$, bee sting $(0.9 \%)$, and eclampsia (0.4\%) [Table 8].

The primary source of sepsis was lung in 26 (46.4\%) AKI patients followed by intraabdominal infections in seven $(12.5 \%)$ patients, central nervous system infections in five $(8.9 \%)$ patients, cellulitis in four (7.1\%) patients, UTI in three $(5.4 \%)$ patients, and unknown source in $11(19.6 \%)$. Of the total 37 snake bite AKI patients, 29 had features of vasculotoxicity, five have features of both vasculotoxicity and neurotoxicity and three had features of neurotoxicity only. Of the vasculotoxic bites, mostly are attributed to Russell's viper bites (90\%) and rest were due to saw scaled viper bites. This conclusion was based on the information obtained from description of the snakes by the patients or witnesses, the actual identification of the dead snake, and the clinical course. Of the total 11 malaria AKI patients, eight patients had falciparum malaria, two had mixed falciparum with vivax malaria, and one had vivax malaria.

Of the total 229 AKI patients enrolled in this study, 65 patients $(28.4 \%)$ died during their hospital stay. AKI patients with sepsis had the highest in-hospital mortality (35.4\%).

\section{Discussion}

In this study, the overall in-hospital mortality among medicine ICU patients with AKI was $28.4 \%$. AKI patients having sepsis had the highest in-hospital mortality $(35.4 \%)$. In previous studies, a mortality rate of $35.9 \%, 38.5 \%$, and $58 \%$ was reported by Peres et al., Oluseyi et al., and Hamzić-Mehmedbašić et al., respectively. ${ }^{[12-14]}$ The variation in the mortality rate observed in these studies may be explained by the difference in the study populations, ICU settings, cause of ICU admission and underlying diseases, or by the nonuniform criteria used for defining AKI in different studies.

The association of age and gender with the in-hospital mortality was not found to be statistically significant in this study, which is in contrast to finding reported by Oluseyi

\begin{tabular}{lc}
$\begin{array}{l}\text { Table 8: Etiology wise distribution of acute kidney injury } \\
\text { patients }\end{array}$ & Frequency, $\boldsymbol{n}$ (\%) \\
\hline Etiology & $56(24.5)$ \\
\hline Sepsis & $37(16.2)$ \\
Snake bite & $29(12.6)$ \\
Acute gastroenteritis & $16(7)$ \\
Cirrhosis & $12(5.2)$ \\
CCF & $11(4.7)$ \\
Malaria & $10(4.4)$ \\
CV stroke & $8(3.5)$ \\
ARDS & $7(3.1)$ \\
Sickle cell disease & $10(4.4)$ \\
Obstructive uropathy & $7(3.1)$ \\
Dengue & $6(2.6)$ \\
OPP & $5(2.2)$ \\
Acute pancreatitis & $4(1.7)$ \\
Contrast - induced & $3(1.3)$ \\
Scrub typhus & $3(1.3)$ \\
HELLP & $2(0.9)$ \\
HUS & $2(0.9)$ \\
Bee sting & $1(0.4)$ \\
Eclampsia & N Number of AKI patients; CCF: Congestive cardiac failure; \\
ARDS: Acute respiratory distress syndrome; OPP: Organophosphorus \\
poisoning; HUS: Hemolytic uremic syndrome; AKI: Acute kidney injury \\
\end{tabular}

et al., Poukkanen et al., Kohli et al., and Shiao et al., where older age was associated with an increased mortality. ${ }^{[13,15-17]}$ Hamzić-Mehmedbašić et al. reported that female gender was related to increased mortality. ${ }^{[14]}$

In this study, the association of comorbidities, i.e., HTN, DM, and IHD with in-hospital mortality was not statistically significant. DM and increased number of comorbidities were found to be related to mortality in AKI patients in the previous studies done by Sezer et al. and Samimagham et al. ${ }^{[18,19]}$

The staging of AKI (severity) was related to in-hospital mortality in this study. Majority of the AKI patients among the nonsurvivors were having Stage 2 and 3 AKI. Similarly, the previous studies done by Oluseyi et al. also reported that advanced AKI or late presentation of AKI was related to increased mortality. ${ }^{[13]}$ Similar findings were also reported by Abosaif et al. and Ostermann and Chang. ${ }^{[20,21]}$

The presence of hypotension and the use of invasive mechanical ventilator in AKI were associated with mortality in this study. 
This association might also reflect severity of illness in subset of our patients having other organ system failure leading to mortality. This finding is comparable with other studies done by Peres et al., Krishnamurthy et al., Liaño and Pascual, Uchino et al., Kaul et al., and Shiao et al. ${ }^{[12,17,22-25]}$

GCS scores and APACHE 2 scores were associated with in-hospital mortality in our AKI patients which is consistent with the results of the previous studies done by Pan et al., Lin et al., Sezer et al., Samimagham et al., Shiao et al., and Friedericksen et al. . $^{[17,18,26-28]}$

"Serum creatinine and blood urea levels on diagnosis of AKI" and "peak rise in creatinine and urea levels within $48 \mathrm{~h}$ of diagnosis of AKI" were associated with in-hospital mortality in our AKI patients. Similarly, Chertow et al. reported that modest changes in serum creatinine concentration were significantly associated with mortality. ${ }^{[29]}$ Serum creatinine $>4 \mathrm{mg} / \mathrm{dL}$ was associated with increased in-hospital mortality in a study by Kaul et al. ${ }^{[25]}$ This finding is also in line with the results of Wilson et al. and Peres et al..$^{[12,30]}$ The metabolic acidosis was associated with in-hospital mortality in AKI patients in this study. The AKI patients in this study having severe metabolic acidosis $(\leq 7 \mathrm{mEq} / \mathrm{L})$ had 2.4 times more risk of mortality in comparison to AKI patients having $\mathrm{HCO}^{3-}$ levels in normal range. Metabolic acidosis was related to in-hospital mortality in studies done by Ostermann and Chang, and Peres et al. ${ }^{[12,21]}$

Hyperkalemia and leukocytosis were related to in-hospital mortality in AKI patients in this study. It may be explained by the association of hyperkalemia and leukocytosis with an advanced AKI and sepsis, respectively, in our AKI patients. Hyperkalemia and the presence of sepsis were related to increased mortality in a study done by Dela Cruz et al. ${ }^{[31]}$

The association of in-hospital mortality with the presence of albuminuria and oliguria was not significant in this study. The presence of oliguria was related to increased mortality in AKI patients in the previous studies reported by Kaul et al., Liaño and Pascual, Dela Cruz et al. and Obialo et al. ${ }^{[23,25,31,32]}$ Similarly, oliguria was found to be an independent predictor of mortality or poor outcome in studies done by Teixeira $\mathrm{C}$ et al., and de Mendonca et al. ${ }^{[33,34]}$

\section{ConcLusion}

The overall in-hospital mortality in patients of AKI admitted to medicine-ICU was $28.4 \%$. Sepsis was the most common cause of AKI (24.5\%). AKI patients having sepsis had the highest in-hospital mortality (35.4\%). The presence of metabolic acidosis, hypotension, GCS and APACHE 2 score, advanced AKI stage, higher serum creatinine and blood urea levels on diagnosis of AKI and the peak rise in their level within $48 \mathrm{~h}$ of diagnosis of AKI, use of mechanical ventilator, leukocytosis, and hyperkalemia were associated with in-hospital mortality in AKI patients.

\section{Financial support and sponsorship}

Nil.

\section{Conflicts of interest}

There are no conflicts of interest.

\section{RefEREnCES}

1. Lameire N, Van Biesen W, Vanholder R. Acute renal failure. Lancet 2005;365:417-30.

2. Thadhani R, Pascual M, Bonventre JV. Acute renal failure. N Engl J Med 1996;334:1448-60.

3. Mehta RL, Pascual MT, Soroko S, Savage BR, Himmelfarb J, Ikizler TA, et al. Spectrum of acute renal failure in the Intensive Care Unit: The PICARD experience. Kidney Int 2004;66:1613-21.

4. Lameire NH, Bagga A, Cruz D, De Maeseneer J, Endre Z, Kellum JA, et al. Acute kidney injury: An increasing global concern. Lancet 2013;382:170-9.

5. Cerdá J, Lameire N, Eggers P, Pannu N, Uchino S, Wang H, et al. Epidemiology of acute kidney injury. Clin J Am Soc Nephrol 2008;3:881-6.

6. Chertow GM, Burdick E, Honour M, Bonventre JV, Bates DW. Acute kidney injury, mortality, length of stay, and costs in hospitalized patients. J Am Soc Nephrol 2005;16:3365-70.

7. Liangos O, Wald R, O'Bell JW, Price L, Pereira BJ, Jaber BL, et al. Epidemiology and outcomes of acute renal failure in hospitalized patients: A national survey. Clin J Am Soc Nephrol 2006;1:43-51.

8. Coca SG, Singanamala S, Parikh CR. Chronic kidney disease after acute kidney injury: A systematic review and meta-analysis. Kidney Int 2012;81:442-8.

9. Schiffl H, Lang SM, Fischer R. Long-term outcomes of survivors of ICU acute kidney injury requiring renal replacement therapy: A 10-year prospective cohort study. Clin Kidney J 2012;5:297-302.

10. Rifkin DE, Coca SG, Kalantar-Zadeh K. Does AKI truly lead to CKD? J Am Soc Nephrol 2012;23:979-84.

11. Khwaja A. KDIGO clinical practice guidelines for acute kidney injury. Nephron Clin Pract 2012;120:c179-84.

12. Peres LA, Wandeur V, Matsuo T. Predictors of acute kidney injury and mortality in an Intensive Care Unit. J Bras Nefrol 2015;37:38-46.

13. Oluseyi A, Ayodeji A, Ayodeji F. Aetiologies and short-term outcomes of acute kidney injury in a tertiary centre in Southwest Nigeria. Ethiop J Health Sci 2016;26:37-44.

14. Hamzić-Mehmedbašić A, Rašić S, Balavac M, Rebić D, Delić-Šarac M, Durak-Nalbantić A, et al. Prognostic indicators of adverse renal outcome and death in acute kidney injury hospital survivors. J Renal Inj Prev 2016;5:61-8.

15. Poukkanen M, Vaara ST, Reinikainen M, Selander T, Nisula S, Karlsson S, et al. Predicting one-year mortality of critically ill patients with early acute kidney injury: Data from the prospective multicenter FINNAKI study. Crit Care 2015;19:125.

16. Kohli HS, Bhat A, Jairam A, Aravindan AN, Sud K, Jha V, et al. Predictors of mortality in acute renal failure in a developing country: A prospective study. Ren Fail 2007;29:463-9.

17. Shiao CC, Ko WJ, Wu VC, Huang TM, Lai CF, Lin YF, et al. U-curve association between timing of renal replacement therapy initiation and in-hospital mortality in postoperative acute kidney injury. PLoS One 2012;7:e42952.

18. Sezer MT, Demir M, Gungor G, Senol A. Predictors of mortality in patients with acute renal failure. Acta Medica (Hradec Kralove) 2006;49:183-8.

19. Samimagham HR, Kheirkhah S, Haghighi A, Najmi Z. Acute kidney injury in Intensive Care Unit: Incidence, risk factors and mortality rate. Saudi J Kidney Dis Transpl 2011;22:464-70.

20. Abosaif NY, Tolba YA, Heap M, Russell J, El Nahas AM. The outcome of acute renal failure in the Intensive Care Unit according to RIFLE: Model application, sensitivity, and predictability. Am J Kidney Dis 2005;46:1038-48.

21. Ostermann M, Chang RW. Acute kidney injury in the Intensive Care Unit according to RIFLE. Crit Care Med 2007;35:1837-43.

22. Krishnamurthy S, Narayanan P, Prabha S, Mondal N, Mahadevan S, Biswal $\mathrm{N}$, et al. Clinical profile of acute kidney injury in a pediatric Intensive Care Unit from Southern India: A prospective observational 
study. Indian J Crit Care Med 2013;17:207-13.

23. Liaño F, Pascual J. Epidemiology of acute renal failure: A prospective, multicenter, community-based study. Madrid Acute Renal Failure Study Group. Kidney Int 1996;50:811-8.

24. Uchino S, Kellum JA, Bellomo R, Doig GS, Morimatsu H, Morgera S, et al. Acute renal failure in critically ill patients: A multinational, multicenter study. JAMA 2005;294:813-8.

25. Kaul A, Sharma RK, Tripathi R, Suresh KJ, Bhatt S, Prasad N, et al. Spectrum of community-acquired acute kidney injury in India: A retrospective study. Saudi J Kidney Dis Transpl 2012;23:619-28.

26. Pan HC, Jenq CC, Tsai MH, Fan PC, Chang CH, Chang MY, et al. Risk models and scoring systems for predicting the prognosis in critically ill cirrhotic patients with acute kidney injury: A prospective validation study. PLoS One 2012;7:e51094.

27. Lin CY, Chang CH, Fan PC, Tian YC, Chang MY, Jenq CC, et al. Serum interleukin-18 at commencement of renal replacement therapy predicts short-term prognosis in critically ill patients with acute kidney injury. PLoS One 2013;8:e66028.

28. Friedericksen DV, van der Merwe L, Hattingh TL, Nel DG, Moosa MR. Acute renal failure in the medical ICU still predictive of high mortality.
S Afr Med J 2009;99:873-5.

29. Chertow GM, Soroko SH, Paganini EP, Cho KC, Himmelfarb J, Ikizler TA, et al. Mortality after acute renal failure: Models for prognostic stratification and risk adjustment. Kidney Int 2006;70:1120-6.

30. Wilson FP, Yang W, Feldman HI. Predictors of death and dialysis in severe AKI: The UPHS-AKI cohort. Clin J Am Soc Nephrol 2013;8:527-37.

31. Dela Cruz CM, Pineda L, Rogelio G, Alano F. Clinical profile and factors affecting mortality in acute renal failure. Ren Fail 1992;14:161-8.

32. Obialo CI, Okonofua EC, Nzerue MC, Tayade AS, Riley LJ. Role of hypoalbuminemia and hypocholesterolemia as copredictors of mortality in acute renal failure. Kidney Int 1999;56:1058-63.

33. Teixeira C, Garzotto F, Piccinni P, Brienza N, Iannuzzi M, Gramaticopolo S, et al. Fluid balance and urine volume are independent predictors of mortality in acute kidney injury. Crit Care 2013;17:R14.

34. de Mendonça A, Vincent JL, Suter PM, Moreno R, Dearden NM, Antonelli $\mathrm{M}$, et al. Acute renal failure in the ICU: Risk factors and outcome evaluated by the SOFA score. Intensive Care Med 2000;26:915-21 